\title{
Fentanyl misuse
}

\author{
Shannon Ruzycki MD, Mark Yarema MD
}

\section{Fentanyl-related deaths are increas- ing worldwide}

More than 1000 fentanyl-related deaths occurred in Canada during 2009-2014. In the United States, an abrupt rise in opioid-related deaths has been attributed to increased fentanyl misuse, resulting in a health advisory from the US Centers for Disease Control and Prevention. ${ }^{2}$

\section{The hallmark of fentanyl toxicity is respiratory depression}

The triad of respiratory depression, miosis and altered level of consciousness represent key features of opioid toxicity and should alert physicians to the possibility of fentanyl poisoning. ${ }^{3}$

\section{Naloxone is an opioid-antagonist that can reverse life-threatening fentanyl overdose}

Naloxone can be delivered (in order of decreasing bioavailability) intravenously, intramuscularly, subcutaneously, endotracheally, intranasally or intralingually. ${ }^{3}$ Reversal of toxicity occurs one to eight minutes after administration. ${ }^{3,4}$ Recent Advanced Cardiovascular Life Support guidelines recommend empiric use of naloxone in treatment algorithms for respiratory depression or cardiac arrest. ${ }^{4} \mathrm{Up}$ to six times the usual 0.4-mg dose of naloxone may be required because of the increased potency of fentanyl compared with other opioids and the unpredictable amount of fentanyl in each pill. ${ }^{3}$

There is a difference between pharmaceutical and nonpharmaceutical fentanyl

Pharmaceutical fentanyl may be extracted for misuse from transdermal patches. The fentanyl is then consumed via inhalation, intravenously or orally. ${ }^{3}$ Nonpharmaceutical fentanyl is synthesized as powder in illicit laboratories. ${ }^{1}$ This powder is cut with other drugs such as heroin and xylazine and pressed into tablets to mimic oxycodone $^{1}$ (Figure 1).

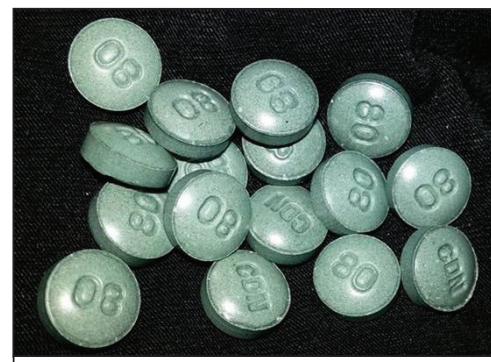

Figure 1: Counterfeit 80-mg oxycodone tablets containing nonpharmaceutical fentanyl confiscated by the Calgary Police Service.

Take-home naloxone (THN) kits are an effective, safe way to reduce fentanylrelated deaths

The kits consist of two doses of intramuscular naloxone, rescue-breathing masks and pamphlets on overdose management. ${ }^{5}$ Seven of the 13 provinces and territories have a dedicated THN program. ${ }^{6}$ Health Canada recently removed naloxone from the Prescription Drug List for emergency use for opioid overdose outside hospital settings, thereby broadening access. ${ }^{6}$ One study has shown that distribution of THN kits in British Columbia reversed 85 opioid overdoses in 20 months. ${ }^{5}$

\section{References}

1. Deaths involving fentanyl in Canada, 2009-2014. In: Bulletin CCENDU. Ottawa: Canadian Centre on Substance Abuse; 2015. Available: www.ccsa.ca/ Resource\%20Library/CCSA-CCENDU-Fentanyl -Deaths-Canada-Bulletin-2015-en.pdf (accessed 2016 Mar. 22).

2. US Centers for Disease Control and Prevention. Increases in fentanyl drug confiscations and fentanylrelated overdose fatalities. Atlanta: CDC Health Alert Network; 2015. Available: emergency.cdc.gov/ han/han00384.asp (accessed 2016 Mar. 22).

3. Boyer EW. Management of opioid analgesic overdose. N Engl J Med 2012;367:146-55.

4. Lavonas EJ, Drennan IR, Gabrielli A, et al. Part 10: special circumstances of resuscitation: 2015 American Heart Association guidelines update for cardiopulmonary resuscitation and emergency cardiovascular care. Circulation 2015;132(Suppl 2):S501-18.

5. Banjo O, Tzemis D, Al-Qutub D, et al. A quantitative and qualitative evaluation of the British Columbia Take Home Naloxone program. CMAJ Open 2014;2:E153-61.
6. The availability of take-home naloxone in Canada. In: Bulletin CCENDU. Ottawa: Canadian Centre on Substance Abuse; 2016. Available: www.ccsa.ca/ Resource\%20Library/CCSA-CCENDU-Take-Home -Naloxone-Canada-2016-en.pdf (accessed 2016 Apr. 6).

\section{Competing interests: None declared.}

This article has been peer reviewed.

Affiliations: Department of Medicine (Ruzycki, Yarema), University of Calgary; Section of Clinical Pharmacology and Toxicology (Yarema), Alberta Health Services; Poison and Drug Information Service (Yarema), Alberta Health Services, Calgary, Alta.

Correspondence to: Shannon Ruzycki, sarro@ualberta.ca

CMAJ 2016. DOI:10.1503/cmaj.151378 